\title{
THE CONSTRUCTION OF AN ASYMPTOTIC CENTER WITH A FIXED-POINT PROPERTY ${ }^{1}$
}

\author{
BY MICHAEL EDELSTEIN
}

Communicated by W. Fuchs, August 16, 1971

AbSTRACT. Given a bounded sequence $\left\{u_{n}: n=1,2, \ldots\right\}$ of points in a closed convex subset $C$ of a uniformly convex Banach space, $c_{m}$ denotes the point in $C$ with the property that among all closed balls centered at points of $C$ and containing $\left\{u_{m}, u_{m+1}, \ldots\right\}$ the one centered at $c_{m}$ is of smallest radius. It is shown that the sequence $\left\{c_{m}: m=1,2, \ldots\right\}$ converges (strongly) to a point $c \in C$ called the asymptotic center of $\left\{u_{n}\right\}$ with respect to $C$. Further, for a class of mappings $f$ of $C$ into itself, which contains all nonexpansive mappings, $f(c)=c$ whenever an $x \in C$ exists such that $f^{n}(x)=u_{n}, n=1,2, \ldots$.

1. Introduction. Let $C$ be a closed convex set in a uniformly convex Banach space $X$. (Recall that $X$ is called uniformly convex if the modulus of convexity

$$
\delta(\varepsilon)=\inf \left\{1-\frac{1}{2}\|x+y\|:\|x\|,\|y\| \leqq 1,\|x-y\| \geqq \varepsilon\right\}
$$

is positive in its domain of definition $\{\varepsilon: 0<\varepsilon \leqq 2\}$.) Given a bounded sequence $\left\{u_{n}: n=1,2, \ldots\right\}$ in the set $C$, define

$$
r_{m}(y)=\sup \left\{\left\|u_{k}-y\right\|: k \geqq m\right\}(y \in X) .
$$

It is well known, and easily proved, that a unique point $c_{m} \in C$ exists such that

$$
r_{m}\left(c_{m}\right)=\inf \left\{r_{m}(y): y \in C\right\}=r_{m} .
$$

Clearly $r_{m} \geqq r_{m+1}$ and $r_{m} \geqq 0$ for all $m=1,2, \ldots$ so that $\left\{r_{m}: m=1,2, \ldots\right\}$ converges to $r=\inf \left\{r_{m}: m=1,2, \ldots\right\}$. We note that if $r=0$ then, as can be readily verified, the sequence $\left\{u_{n}\right\}$ converges.

\section{The asymptotic center.}

Definition. If $\left\{c_{m}\right\}$ converges then $c=\lim c_{n}$ is called the asymptotic center of $\left\{u_{n}\right\}$ (with respect to $C$ ).

THEOREM 1. With $X, C$ and $\left\{u_{n}\right\}$ as above, the sequence $\left\{c_{m}\right\}$ converges. (Thus the asymptotic center c exists.)

Proof. If $r=0$ then, as can be readily seen, $\left\{u_{n}\right\}$ is a Cauchy sequence and $\lim _{n \rightarrow \infty} u_{n}=\lim _{m \rightarrow \infty} c_{m}(=c)$. We may then assume that $r>0$. Suppose now, for a contradiction, that $\left\{c_{m}\right\}$ fails to converge. Then an $\varepsilon>0$ exists such that for any natural number $N$ there are integers

AMS 1969 subject classifications. Primary 4785; Secondary 5485.

Key words and phrases. Asymptotic center, fixed-point theorem, nonexpansive mappings.

${ }_{1}$ This research was supported by the National Research Council of Canada, Grant A-3999. 
$n>m \geqq N$ with $\left\|c_{m}-c_{n}\right\| \geqq \varepsilon$. From the uniform convexity of $X$ and the fact that

$$
\begin{array}{rlrl}
\left\|u_{k}-c_{n}\right\| & \leqq r_{n} \leqq r_{m} & & (k \geqq n), \\
\left\|u_{k}-c_{m}\right\| \leqq r_{m} & & (k \geqq m),
\end{array}
$$

it follows that

$$
\begin{aligned}
\left\|u_{k}-\frac{c_{m}+c_{n}}{2}\right\| & \leqq r_{m}\left(1-\delta\left(\frac{\left\|c_{m}-c_{n}\right\|}{r_{m}}\right)\right) \\
& \leqq r_{m}(1-\delta(\varepsilon / D)) \quad(k \geqq n),
\end{aligned}
$$

where $D$ is the diameter of $\left\{u_{n}\right\}$. On the other hand, since $\frac{1}{2}\left(c_{m}+c_{n}\right) \neq c_{n}$, there is a $k \geqq n$ such that

$$
r_{n}<\left\|u_{k}-\frac{c_{m}+c_{n}}{2}\right\|
$$

For such a $k$, (3) and (4) hold simultaneously so that $r_{m}-r_{n} \geqq r_{m} \delta(\varepsilon / D)$ $\geqq r \delta(\varepsilon / D)$. This, however, is impossible since $\left\{r_{k}\right\}$ converges.

REMARK. If $X$ is a Hilbert space then $c$ belongs to the closed convex hull of $\left\{u_{n}\right\}$. (This follows immediately from the fact that the same assertion holds for each $c_{m}, m=1,2, \ldots$.)

\section{A fixed-point theorem.}

THEOREM 2. Let $C,\left\{u_{n}\right\}$ and $c\left(=\lim _{m \rightarrow \infty} c_{m}\right)$ be as in Theorem 1 and $f: C \rightarrow C$ be a mapping of $C$ into itself satisfying the following conditions:

(1) $u_{n}=f^{n}(x)$ for some $x \in C$ and all $n=1,2, \ldots$;

(2) there exists a positive integer $n_{0}$ and neighborhood $V$ of $c$ in $C$ such that

$$
\left\|f^{k}(x)-f(v)\right\| \leqq\left\|f^{k-1}(x)-v\right\| \quad\left(k \geqq n_{0}, v \in V\right) .
$$

Then $f(c)=c$.

Proof. If $r=0$ then $c=\lim _{n \rightarrow \infty} u_{n}=\lim _{n \rightarrow \infty} f^{n}(x)$ and $f(c)=c$. Let then $r$ be positive and suppose that $f(c) \neq c$. Set $\eta=\|c-f(c)\|$ and choose $N \geqq n_{0}$ large enough so that $c_{n} \in V,\left\|c-c_{n}\right\| \leqq \eta / 3$ and $\| f(c)$ $-f\left(c_{n}\right) \| \leqq \eta / 3$ for $n \geqq N$; and, therefore, $\left\|c_{n}-f\left(c_{n-1}\right)\right\| \geqq \eta / 3$ for all $n \geqq N+1$. Now, for all $k$ and $n$ with $k \geqq n \geqq N+1$ we have

$$
\begin{aligned}
\left\|f^{k}(x)-c_{n}\right\| & \leqq r_{n} \leqq r_{n-1}, \\
\left\|f^{k}(x)-f\left(c_{n-1}\right)\right\| & \leqq\left\|f^{k-1}(x)-c_{n-1}\right\| \leqq r_{n-1} .
\end{aligned}
$$


By uniform convexity then

$$
\begin{aligned}
\left\|f^{k}(x)-\frac{c_{n}+f\left(c_{n-1}\right)}{2}\right\| & \leqq r_{n-1}\left(1-\delta\left(\frac{\eta}{3 r_{n-1}}\right)\right) \\
& \leqq r_{n-1}\left(1-\delta\left(\frac{\eta}{3 D}\right)\right) \quad(k \geqq n \geqq N+1),
\end{aligned}
$$

where again $D$ denotes the diameter of $\left\{u_{n}\right\}=\left\{f^{n}(x)\right\}$. On the other hand, since $\left(c_{n}+f\left(c_{n-1}\right)\right) / 2 \neq c_{n}$, there is a $k \geqq n$ such that

$$
r_{n}<\left\|f^{k}(x)-\frac{c_{n}+f\left(c_{n-1}\right)}{2}\right\| .
$$

Thus $r_{n}<r_{n-1}(1-\delta(\eta / 3 D))$ and $r_{n-1}-r_{n}>r_{n-1} \delta(\eta / 3 D) \geqq r \delta(\eta / 3 D)$. This, however, is impossible as $\left\{r_{n}\right\}$ converges.

\section{An immediate consequence of Theorem 2 is the following.}

Corollary. Let $C$ be a closed and bounded convex set in a uniformly convex Banach space and suppose that $f$ is a continuous mapping of $C$ into itself such that for each $x \in C$ there is a positive integer $N=N(x)$ such that, for all integers $n \geqq N$ and all $y \in C$,

$$
\left\|f^{n}(x)-f^{n}(y)\right\| \leqq\left\|f^{n-1}(x)-f^{n-1}(y)\right\| .
$$

Then $f(\xi)=\xi$ for some $\xi \in C$.

Remark. The well-known theorem of Browder [1] and Göhde [2], asserting that each nonexpansive mapping of a closed and bounded convex subset of a uniformly convex Banach space into itself has a fixed point, follows from the above corollary upon setting $N=1$ (for all $x \in C$ ).

\section{REFERENCES}

1. F. E. Browder, Nonexpansive nonlinear operators in a Banach space, Proc. Nat. Acad. Sci. U.S.A. 54 (1966), 1041-1044. MR 32 \# 4574.

2. D. Göhde, Zum Prinzip der kontraktiven Abbildung, Math. Nachr. 30 (1965), 251-258. MR 32 \# 8129.

Department of Mathematics, Dalhousie University, Halifax, Nova Scotia, CANADA

Current address: Department of Mathematics, University of California, Berkeley, California 94720 